\title{
Prognostic Significance of Preoperative Anemia, Leukocytosis and Thrombocytosis in Chinese Women with Epithelial Ovarian Cancer
}

\author{
Ying Chen ${ }^{1,2,3 *}$, Lei Zhang ${ }^{1,2,3}$, Wen-Xin Liu ${ }^{1}$, Xiang-Yu Liu ${ }^{1}$
}

\begin{abstract}
Malignant tumors are often accompanied by increased risk of hematological abnormalities. However, few studies have reported any prognostic impact of preoperative thrombocytosis, leukocytosis and anemia in epithelia ovarian cancer (EOC). This study aimed to investigate preoperative hematological parameters for anemia, leukocytosis and thombocytosis in relation to established prognostic factors and survival in EOC cases. A total of 816 Chinese women treated for EOC were retrospectively included in the study focusing on the relationship between preoperative hemoglobin, leukocyte and platelet counts, and a panel of clinicopathologic characteristics and outcome. Preoperative anemia was present in $13.4 \%$, leukocytosis in $16.7 \%$ and thrombocytosis in $22.8 \%$. Additionally, EOC patients with low differentiation grade, advanced stage, lymph node (LN) metastasis, residual disease $\geq 1 \mathrm{~cm}$, ascites volume $>1,000 \mathrm{ml}$, serum cancer antigen 125 (CA125) $>675 \mathrm{U} / \mathrm{ml}$, and disease recurrence had the higher prevalence of preoperative anemia, leukocytosis and thrombocytosis (all $p<0.05$ ). Moreover, EOC patients with older age or postmenopausal EOC patients had the higher prevalence of thrombocytosis (28.7\% vs $\mathbf{1 7 . 3 \%}$ or $\mathbf{2 6 . 0 \%}$ vs $\mathbf{1 7 . 7 \%}$ ). Furthermore, in a Cox proportional hazard model, thrombocytosis was an independent factor for progression-free survival (PFS) and overall survival (OS) $(p<0.001)$. Conclusively, preoperative anemia, leukocytosis or thrombocytosis in EOC patients is closely associated with more malignant disease phenotype and poorer prognosis. Significantly, thrombocytosis may independently predict the diseasespecific survival for EOC patients.
\end{abstract}

Keywords: Epithelial ovarian cancer - anemia - leukocytosis - thrombocytosis - prognosis

Asian Pac J Cancer Prev, 16 (3), 933-939

\section{Introduction}

Approximately $95 \%$ of ovarian cancers are of epithelial origin. In 2013, there were 22,240 estimated new diagnoses of ovarian cancer and 14,030 deaths from the disease (Siegel et al, 2013). The high mortality of epithelial ovarian cancer (EOC) is mainly due to latestage diagnosis for more than $70 \%$ of patients. Recently, paraneoplastic syndromes have been proved in playing a causal role in poor prognosis for EOC (Cho et al., 2012; Stone et al., 2012). Paraneoplastic syndromes include signs and symptoms, which are not attributable to direct tumor invasion, but rather the consequence of the presence of neoplastic cells somewhere in the body. Hematological manifestations can include anemia, leukocytosis or thrombocytosis and are typically observed in advanced cancers (Pelosof, 2010). Previous studies had demonstrated anemia had been linked to advanced disease and poor prognosis for several cancer types originating from different organ systems including gastrointestinal tract (Qiu et al., 2010), breast (Qiu et al., 2010), head and neck (Cordella et al., 2011), lung (Holgersson et al., 2012), ovary (Gerestein et al., 2009) and endometrium (Njolstad, et al., 2013). Leukocytosis had been shown to be a prognostic factor in non-small cell lung cancer (Holgersson et al., 2012) and cervical cancer (Mabuchi et al., 2011). Moreover, thrombocytosis had been certified to be the well-known consequence of malignant disease and independent prognostic factors in endometrial cancer (Njolstad et al., 2013) and ovarian cancer (Stone et al., 2012).

However, to our knowledge, an investigation evaluating prognostic values of anemia, leukoctosis and thrombocytosis synchronously in EOC has not bee reported. On this background, we carried out this retrospective study of preoperative hematological assessments of hemoglobin, leukocyte and platelet count in relation to a comprehensive panel of clinicopathologic variables and outcome in a population based cohort of Chinese women treated for EOC. 


\section{Materials and Methods}

With institutional review board approval, clinicopathologic information was collected from consenting patients diagnosed and treated for EOC between January 2001 and December 2011 at Department of Gynecologic Oncology, Tianjin Medical University Cancer Institute and Hospital. Clinical data from 900 consecutive patients were extracted with routine preoperative hematological counts. Twenty-twelve patients with concomitant endometrial cancer were excluded due to possible confounding neoplastic effect on hematopoiesis, while 62 patients were excluded with a previous history of cancer (ten patients with breast cancer, fifteen with colon cancer, twelve with rectum cancer and twenty-five with other cancers), leaving 816 patients for further analysis.

Among 816 patients, 214 cases were not received

Table 1. Clinicopathologic Characteristics, Demographics and Preoperative Hematological Values For 816 EOC Patients

\begin{tabular}{|c|c|}
\hline Age (years) & Median: 53; Range: 21-79 \\
\hline BMI $\left(\mathrm{kg} / \mathrm{m}^{2}\right)$ & Median: 23; Range: 15-47 \\
\hline \multicolumn{2}{|l|}{ Menopausal status } \\
\hline Yes & $500(61.3 \%)$ \\
\hline No & $316(38.7 \%)$ \\
\hline \multicolumn{2}{|l|}{ Histology } \\
\hline serous & $578(70.8 \%)$ \\
\hline mucous and others & $238(29.2 \%)$ \\
\hline \multicolumn{2}{|l|}{ Differentiation } \\
\hline G1-2 & $367(45.0 \%)$ \\
\hline G3 & $449(55.0 \%)$ \\
\hline \multicolumn{2}{|l|}{ FIGO Stage (2009) } \\
\hline I-II & $232(28.4 \%)$ \\
\hline III-IV & $584(71.6 \%)$ \\
\hline With Lymphadnectomy & $630(77.2 \%)$ \\
\hline Pelvic & $526(83.5 \%)$ \\
\hline Para-aortic+pelvic & $104(16.5 \%)$ \\
\hline Removed Lymph nodes & Median: 25; Range: 12-57 \\
\hline \multicolumn{2}{|l|}{ Lymph nodes metastasis } \\
\hline No & $637(78.1 \%)$ \\
\hline Yes & $179(21.9 \%)$ \\
\hline \multicolumn{2}{|l|}{ Residual Disease } \\
\hline$<1 \mathrm{~cm}$ & $602(73.8 \%)$ \\
\hline$\geq 1 \mathrm{~cm}$ & $214(26.2 \%)$ \\
\hline Ascites volume (ml) & Median: 1000; Range: 200-7000 \\
\hline$\leq 1000$ & $595(72.9 \%)$ \\
\hline$>1000$ & $221(27.1 \%)$ \\
\hline Serum CA125 (U/ml) & Median: 675; Range: $23-7400$ \\
\hline$\leq 675$ & $508(62.3 \%)$ \\
\hline$>675$ & $308(37.7 \%)$ \\
\hline Hemoglobin count $(\mathrm{g} / \mathrm{dl})$ & Median: 12.2 ; Range: 6.1-16.2 \\
\hline Normal & $707(86.6 \%)$ \\
\hline Anemia & $109(13.4 \%)$ \\
\hline Leukocyte count (109/L) & Median: 6.4 ; Range: $1.93-19.8$ \\
\hline Normal & $680(83.3 \%)$ \\
\hline Leukocytosis & $136(16.7 \%)$ \\
\hline Platelet count (109/L) & Median: 262 ; Range: 95-696 \\
\hline Normal & $630(77.2 \%)$ \\
\hline Thrombocytosis & $186(22.8 \%)$ \\
\hline
\end{tabular}

*Anemia defined as hemoglobin value $<12 \mathrm{~g} / \mathrm{dl}$ blood; Leukocytosis defined by leukocyte count $>10 \times 10^{9}$ cells $/ \mathrm{L}$ blood; Thrombocytosis defined as platelet count $>400 \times 10^{9}$ cells/ $/ \mathrm{L}$ blood pelvic or Para-aortic and pelvic lymphadenectomy owing to these patients with residual disease $\geq 1 \mathrm{~cm}$. Neo-adjuvant chemotherapy was given for 154 patients and 798 patients were received adjuvant treatment after surgery.

Age, FIGO stage, histologic subtype, histologic grade, residual disease, serum cancer antigen 125 (CA125), ascites volume, lymph node (LN) status, events of recurrence, and patient status during follow-up period were extracted from available follow-up records. Overall survival (OS) was defined as the time interval from the date of primary surgery to the date of death (failure) or to the end of follow-up for women who were alive (censored). Progression-free survival (PFS) was defined as the time elapsed from the date of primary surgery to the appearance of disease recurrence or progression (failure) or the last follow-up for women who were alive with no A

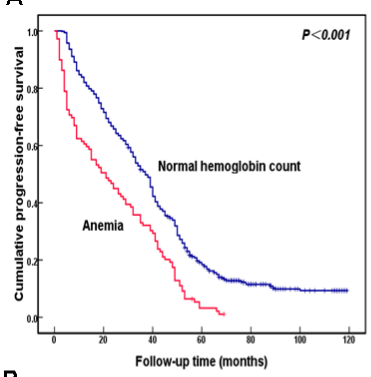
D

B

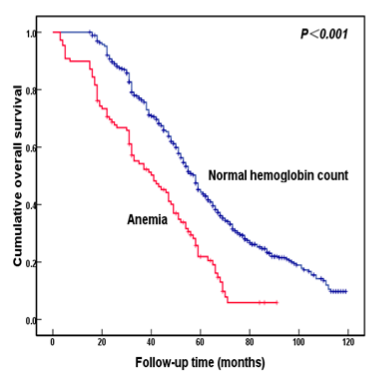

C
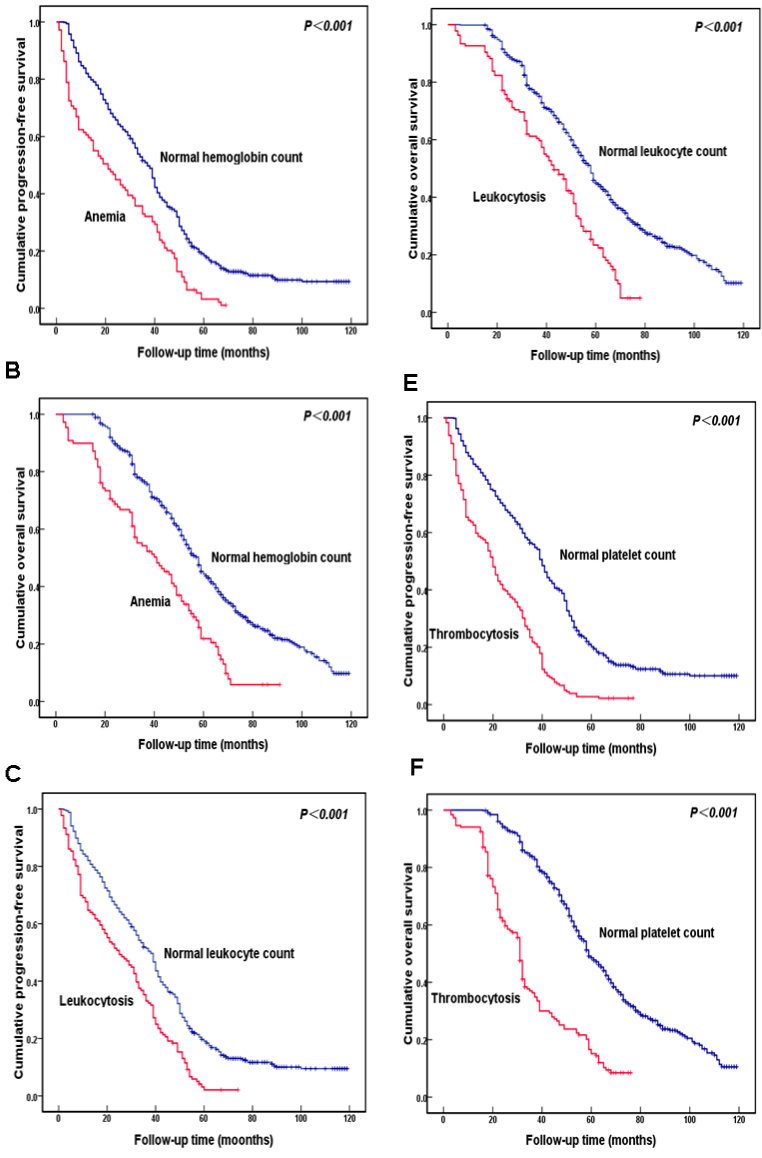

E

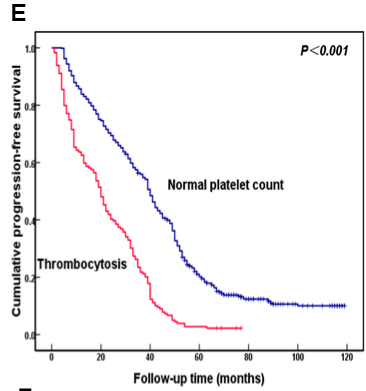

$\mathbf{F}$

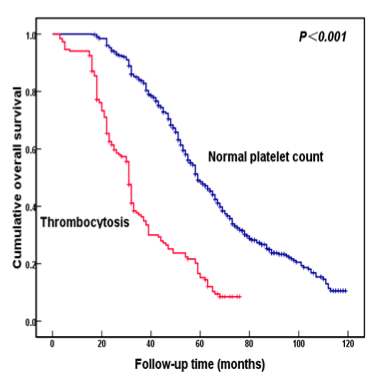

Figure 1. Progression-free Survival (PFS) and Overall Survival (OS) for Epithelial Ovarian Cancer (EOC) Patients with Preoperative Anemia, Leukocytosis and Thrombocytosis by Kaplan-Meier Curves. A) EOC Patients with anemia had the shorter median of PFS than patients with normal hemoglobin count (21 vs 37 months, $p<0.001$ ); B) EOC Patients with anemia had the shorter median OS than patients with normal hemoglobin count (41 vs 58 months, $p<0.001)$; C) EOC patients with leukocytosis had the shorter median of PFS than patients with normal leukocyte count ( $25 \mathrm{vs}$ 38 months, $p<0.001$ ); D) EOC patients with leukocytosis had the shorter median OS than patients with normal leukocyte count (43 vs 58 months, $p<0.001)$; E) EOC patients with thrombocytosis had the shorter median of PFS than patients with normal hemoglobin count (11 vs 40months, $p<0.001)$; F) EOC patients with thrombocytosis had the shorter median of OS than patients with normal hemoglobin count (31 vs 59 months, $p<0.001$ ) 
Prognostic Significance of Anemia, Leukocytosis and Thrombocytosis in Chinese Women with Ovarian Cancer

evidence of disease recurrence or progression (censored). All patients were followed until death or the end of the follow-up period (August 31, 2013).

EDTA-blood samples were routinely collected at hospital admission before primary treatment hospitalization work-up. Hematological results for hemoglobin, leukocyte and platelet counts were obtained from patients' files available through our institution's biochemical database. Blood samples prior to primary treatment were aspired. Sixteen patients received repeated blood transfusions preoperatively to promote safer surgery, and consequently 28-to 30-day-old pre-transfusion samples were used for these cases.

For statistical analysis, SPSS Statistical Package for the Social Sciences, version 18.0 (Chicago, IL, USA) was applied. The results were considered statistically significant with a probability of less than 0.05 . Patients were categorized into low and high subgroups according to the medians of the continuous data (age at primary treatment, serum CA125 and ascites volume). The chisquared and Fisher's exact tests were applied in analysis of categorical variable. The survival rate was determined by the Kaplan-Meier method, and the log rank test was used to determine significance. Factors that were deemed of potential importance by univariate analysis were included in the multivariate analysis. Associations are shown as hazard ratios (HR) and 95\% confidence intervals (CI).

Anemia was defined as a blood hemoglobin concentration of $<12 \mathrm{~g} / \mathrm{dL}$ according to WHO global standards for non-pregnant women. Leukocytosis was defined as white blood cell count of $>10 \times 10^{9}$ cells $/ \mathrm{L}$ and thrombocytosis as platelet count of $>400 \times 10^{9}$ platelets $/ \mathrm{L}$, the latter two representing cut-offs for the adult female population in China.

\section{Results}

\section{Patient characteristics and demographics}

Clinicopathologic and demographic characteristics of our study cohort are presented in Table 1 . Preoperative hemoglobin values ranged from $6.1 \mathrm{~g} / \mathrm{dL}$ to $16.2 \mathrm{~g} / \mathrm{dL}$ with a mean \pm SD of $12.0 \pm 1.80 \mathrm{~g} / \mathrm{dL}$ and a median of 12.2 $\mathrm{g} / \mathrm{dL}$ with a $13.4 \%$ prevalence of anemia. Preoperative leukocyte counts (leukocytes per liter) ranged from $1.93 \times$ $10^{9} / \mathrm{L}$ to $19.8 \times 10^{9} / \mathrm{L}$ with a mean $\pm \mathrm{SD}$ of $6.8 \pm 2.80 \times 10^{9} / \mathrm{L}$, a median of $6.4 \times 10^{9} / \mathrm{L}$ and a $16.7 \%$ prevalence of leukocytosis. Preoperative platelet counts (platelets per liter) ranged from $95 \times 10^{9} / \mathrm{L}$ to $696 \times 10^{9} / \mathrm{L}$ with a mean \pm SD of $255 \pm 84 \times 10^{9} / \mathrm{L}$, a median of $262 \times 10^{9} / \mathrm{L}$ and a $22.8 \%$ prevalence of thrombocytosis. Only 20 patients fulfilled the criteria for all three; anemia, thrombocytosis and leukocytosis at preoperative evaluation, while 62 patients had a combination of two out of three hematological manifestations.

Preoperative anemia, leukocytosis and thrombocytosis associated with clinic characteristics in 816 EOC patients

As shown in Table 2, the higher prevalence of

Table 2. Correlation between Preoperative Anemia, Leukocytosis and Thrombocytosis and Clinicopathologic Phenotype in 816 EOC Patients

\begin{tabular}{|c|c|c|c|c|c|c|c|}
\hline Variables & $\begin{array}{l}\text { Cases } \\
(\mathrm{N})\end{array}$ & $\begin{array}{l}\text { Anemia } \\
\mathrm{N}(\%)\end{array}$ & $p$ & $\begin{array}{l}\text { Leukocytosis } \\
\qquad \mathrm{N}(\%)\end{array}$ & $p$ & $\begin{array}{c}\text { Thrombocytosis } \\
\mathrm{N}(\%)\end{array}$ & $p$ \\
\hline $\begin{array}{l}\text { Age at primary treatment } \\
\text { (year) }\end{array}$ & $\begin{array}{l}\leq 53 \\
>53\end{array}$ & $\begin{array}{l}422 \\
394\end{array}$ & $\begin{array}{l}0.626 \\
54(12.8) \\
55(14.0)\end{array}$ & $\begin{array}{l}70(16.6) \\
66(16.8)\end{array}$ & 0.95 & $\begin{array}{r}73(17.3) \\
113(28.7)\end{array}$ & $<0.001$ \\
\hline Menopausal status & $\begin{array}{l}\text { Yes } \\
\text { No }\end{array}$ & $\begin{array}{l}500 \\
316\end{array}$ & $\begin{array}{l}0.964 \\
67(13.4) \\
42(13.3)\end{array}$ & $\begin{array}{l}79(15.8) \\
57(18.0)\end{array}$ & 0.403 & $\begin{array}{r}130(26.0) \\
56(17.7)\end{array}$ & 0.006 \\
\hline Histology & $\begin{array}{l}\text { serous } \\
\text { mucous and others }\end{array}$ & $\begin{array}{l}578 \\
238\end{array}$ & $\begin{array}{l}0.16 \\
71(12.3) \\
38(16.0)\end{array}$ & $\begin{array}{l}88(15.2) \\
48(20.2)\end{array}$ & 0.085 & $\begin{array}{r}125(21.6) \\
61(25.6)\end{array}$ & 0.215 \\
\hline Differentiation & $\begin{array}{l}\text { G1-2 } \\
\text { G3 }\end{array}$ & $\begin{array}{l}367 \\
449\end{array}$ & $\begin{array}{l}<0.001 \\
29(7.9) \\
80(17.8)\end{array}$ & $\begin{array}{l}46(12.5) \\
90(20.0)\end{array}$ & 0.004 & $\begin{array}{r}37(10.1) \\
149(33.2)\end{array}$ & $<0.001$ \\
\hline FIGO Stage (2009) & $\begin{array}{l}\text { I-II } \\
\text { III-IV }\end{array}$ & $\begin{array}{l}232 \\
584\end{array}$ & $\begin{array}{l}0.003 \\
18(7.8) \\
91(15.6)\end{array}$ & $\begin{array}{l}24(10.3) \\
112(19.2)\end{array}$ & 0.002 & $\begin{array}{r}32(13.8) \\
154(26.4)\end{array}$ & $<0.001$ \\
\hline Lymph nodes metastasis & $\begin{array}{l}\text { No } \\
\text { Yes }\end{array}$ & $\begin{array}{l}637 \\
179\end{array}$ & $\begin{array}{l}<0.001 \\
64(10.0) \\
45(25.1)\end{array}$ & $\begin{array}{l}91(14.3) \\
45(25.1)\end{array}$ & 0.001 & $\begin{array}{r}111(17.4) \\
75(41.9)\end{array}$ & $<0.001$ \\
\hline Residual disease & $\begin{array}{l}<1 \mathrm{~cm} \\
\geq 1 \mathrm{~cm}\end{array}$ & $\begin{array}{l}602 \\
214\end{array}$ & $\begin{array}{l}<0.001 \\
64(10.6) \\
45(21.0)\end{array}$ & $\begin{array}{l}83(13.8) \\
53(24.8)\end{array}$ & $<0.001$ & $\begin{array}{r}79(13.1) \\
107(50.0)\end{array}$ & $<0.001$ \\
\hline $\begin{array}{l}\text { Ascites volume } \\
(\mathrm{ml})\end{array}$ & $\begin{array}{l}\leq 1000 \\
>1000\end{array}$ & $\begin{array}{l}595 \\
221\end{array}$ & $\begin{array}{l}0.008 \\
68(11.4) \\
41(18.6)\end{array}$ & $\begin{array}{l}85(14.3) \\
51(23.1)\end{array}$ & 0.003 & $\begin{array}{r}123(20.7) \\
63(28.5)\end{array}$ & 0.018 \\
\hline $\begin{array}{l}\text { Serum CA125 } \\
(\mathrm{U} / \mathrm{ml})\end{array}$ & $\begin{array}{l}\leq 675 \\
>675\end{array}$ & $\begin{array}{l}508 \\
308\end{array}$ & $\begin{array}{l}<0.001 \\
48(9.4) \\
61(19.8)\end{array}$ & $\begin{array}{l}67(13.2) \\
69(22.4)\end{array}$ & $<0.001$ & $\begin{array}{r}103(20.3) \\
83(26.9)\end{array}$ & 0.028 \\
\hline Recurrence & $\begin{array}{l}\text { No } \\
\text { Yes }\end{array}$ & $\begin{array}{r}89 \\
727\end{array}$ & $\begin{array}{l}0.001 \\
2(2.2) \\
107(14.7)\end{array}$ & $\begin{array}{l}5(5.6) \\
131(18.0)\end{array}$ & 0.003 & $\begin{array}{c}5(5.6) \\
181(24.9)\end{array}$ & $<0.001$ \\
\hline
\end{tabular}


Table 3. Univariate and Multivariate Survival Analysis of the Prognostic Factors for Progression-free and Overall Survival in 816 EOC Patients

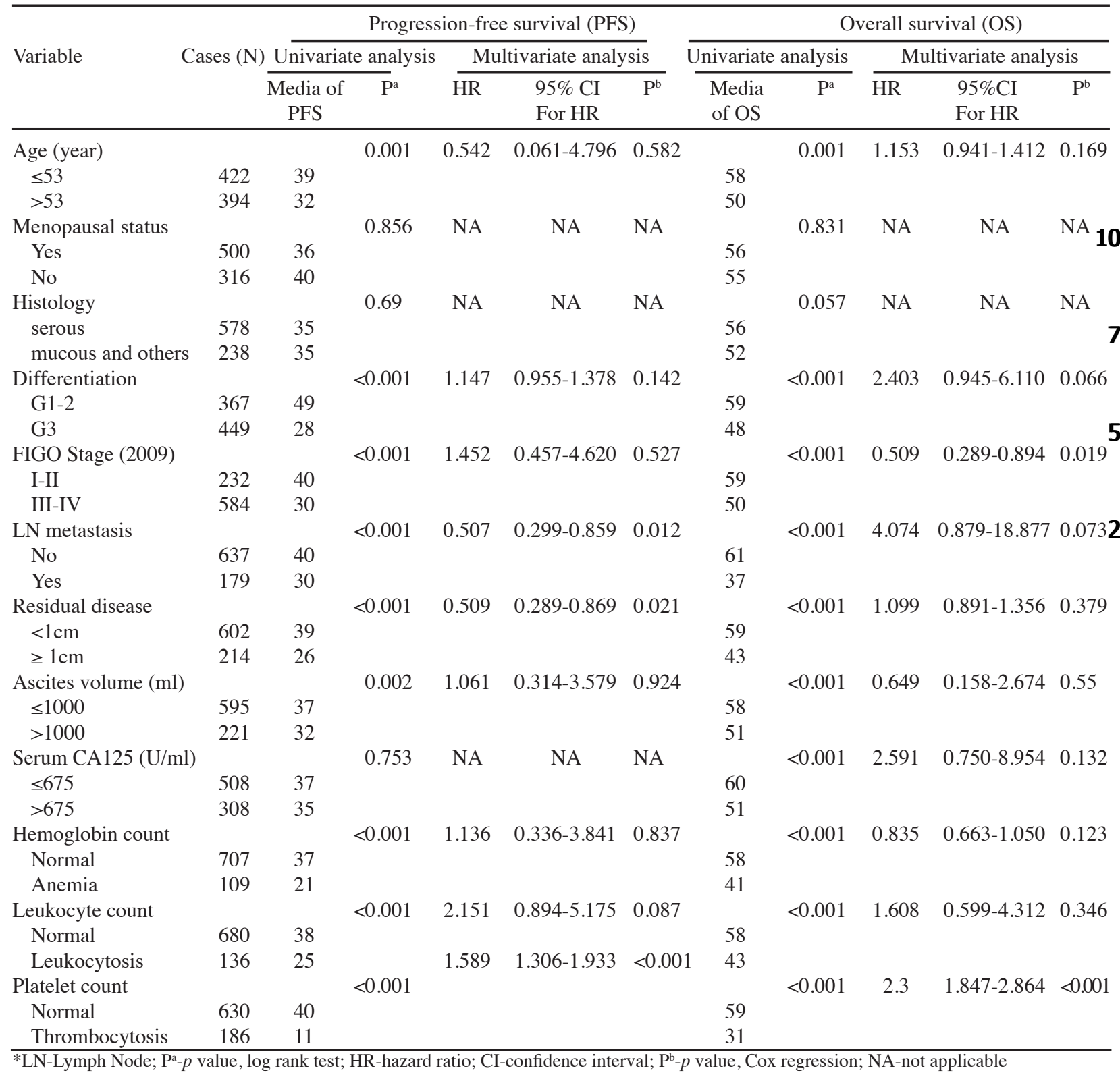

preoperative anemia, leukocytosis and thrombocytosis were closely related to EOC patients with low differentiated, advanced stage, LN metastasis, residual disease $\geq 1 \mathrm{~cm}$, ascites volume $>1000 \mathrm{ml}$, serum CA125 $>675 \mathrm{U} / \mathrm{ml}$, and disease recurrence (all $p<0.05$ ). Additionally, EOC patients with older age and postmenopausal EOC patients had the higher prevalence of thrombocytosis, respectively $(28.7 \%$ vs $17.3 \%$ and $26.0 \%$ vs $17.7 \%$ ). Overall, these results suggested that preoperative anemia, leukocytosis, and thrombocytosis were associated with a more malignant EOC phenotype.

Univariate and multivariate analysis for determinants of PFS and OS in 816 EOC patients

The patient cohort had a follow-up time from 0 to 140 months after primary treatment, with a median follow-up time of 65 months. By univariate analysis, the shorter median of OS and PFS were related to older age, low differentiated, advanced stage, LN metastasis, residual disease $\geq 1 \mathrm{~cm}$, ascites volume $>1000 \mathrm{ml}$, anemia, leukocytosis, and thrombocytosis ( $p<0.05$, Table 3$)$. Furthermore, shorter media of OS was also related to serum CA125>675 U/ml ( $p<0.001$, Table 3$)$.

These significant variables detected by univariate analysis were included in multivariate analysis. In Cox proportional hazard model, LN metastasis, residual disease $\geq 1 \mathrm{~cm}$, and thrombocytosis were the independent factors for the evaluation of PFS $(p<0.05$, Table 3$)$. Additionally, advanced stage and thrombocytosis were the independent factors for the evaluation of OS ( $p<0.05$, Table 3). Thus, EOC patients with thrombcytosis showed shorter PFS and OS than patients with normal platelet counts.

Kaplan-Meier survival curves are displayed in Figure 1. EOC Patients with anemia had the shorter medians of PFS and OS than patients with normal hemoglobin count, respectively (21 and 41 months vs 37 and 58 months, $p<0.001$, Figure $1 \mathrm{~A}$ and $1 \mathrm{~B})$. EOC patients with leukocytosis had the shorter medians of PFS and OS than patients with normal leukocyte count, respectively 
(25 and 43 months $v s 38$ and 58 months, $p<0.001$, Figure $1 \mathrm{C}$ and 1D). EOC patients with thrombocytosis had the shorter medians of PFS and OS than patients with normal hemoglobin count, respectively (11 and 31 months vs 40 and 59 months, $p<0.001$, Figure $1 \mathrm{E}$ and $1 \mathrm{~F})$.

\section{Discussion}

Serologic measurement for EOC patients, including CA125, albumin, hemoglobin, and leukocyte, and platelet levels, had emerged as potential preoperative predictors of outcome (Gungor, et al., 2009; Wheler et al., 2009; Herzog et al., 2011). In general, tumors can affect hematopoietic parameters by significant tumor bleed, or by affecting hematopoiesis through infiltration into the bone marrow or by production of pro-inflammatory cytokines and free radicals that damage hematopoietic progenitor cells, which often were regarded as "paraneoplastic syndromes"(Ashour, et al., 1997; Weiss et al., 2005). Our population based study found the prevalence of anemia, leukocytosis and thrombocytosis of $13.4 \%, 16.7 \%$ and $22.8 \%$, and also demonstrated that preoperative anemia, leukocytosis, and thrombocytosis were associated with a more malignant EOC phenotype.

Anemia has been linked to advanced disease and poor prognosis for several cancer types originating from different organ systems including gastrointestinal tract (Qiu et al., 2010), breast (Qiu et al., 2010), head and neck (Cordella et al., 2011), and lung (Tomita, et al., 2008; Holgersson et al., 2012). Our study also showed that anemia is a strong predictor of shorter PFS or OS in EOC patients. Probable explanations for cancer patients suffering from anemia include disorders of iron metabolism (Cullis, 2013), extracorpuscular hemolysis and catabolism of patients with tumor burden (Dicato, et al., 2010). Significantly, the observed anemia maybe also related to paracrine signaling factors affecting erythropoiesis, such as the pro-inflammatory cytokines interleukin-1 and tumor necrosis factor $\alpha$ (Seo et al., 2004). Attention has also been given recently to the role of erythropoietin (Epo) expression and erythropoietin receptor (Epo-R) expression in cancerous cells (Hardee, et al., 2006). Previous studies showed Epo was involved in growth and angiogenesis in endometrial cancer through increased expression of mRNAs for both Epo and Epo-R and increased Epo-R expression in tumors is in turn associated with advanced-stage disease and LN metastasis (Yasuda et al., 2002; Acs, et al., 2004).

Till now, less is known about the association of pretreatment peripheral white blood cells and prognosis in patients with malignant diseases. A study on metastatic gastric cancer identified that pretreatment absolute granulocyte count of $<6,000 / \mathrm{mm}^{3}$, lymphocyte count of $>1,500 / \mathrm{mm}^{3}$ and monocyte count of $3,000-9,000 /$ $\mathrm{mm}^{3}$ were independent predictors of poor prognosis (Jung et al., 2011). Additionally, several studies had also demonstrated that leukocytosis was closely associated with tumor progression and was the poor prognostic factor for lung (Holgersson et al., 2012), colon (Mroczko et al., 2007), endometrial (Njolstad et al., 2013) and cervical cancer (Mabuchi et al., 2011). Similarly, in this study, we found that EOC patients with more malignant disease phenotype had the higher prevalence of leukocytosis, while the shorter PFS and OS. As for the exact mechanism of leukocytosis being associated with worse survival and unfavorable clinicopathologic findings maybe the theories of inflammatory events with systemic manifestation elicited by cancer cells in tumorigenesis (Grivennikov, et al., 2010; Hanahan et al., 2011). An inflammatory response to tumor taking place by neutrophils-releasing inflammatory cytokines, leukocytic and other phagocytic mediators that would induce damage to cellular DNA, inhibit apoptosis and promote angiogenesis around cancer area, which would result in tumor growth, progression, and metastasis (Antonioli, et al., 2013). However, whether this leukocytosis is a paraneoplastic effect, a manifestation of intrinsic or extrinsic pathways affecting the EOC cells, or confounded by tumor-induced chronic inflammation in abdominal cavity of variable severity, cannot be explained by our study, which deserved further study.

Previous study had proved that thrombocytosis is associated with clinical features of patients and correlates with a poor prognosis in gastric cancer (Li et al., 2014). Unal D et al. also reported the platelet to lymphocyte ratio was a useful predictor of treatment response and prognosis in patients with non-small cell lung cancer (Unal, et al., 2013). Furthermore, thrombocytosis is also a well-known consequence of malignant disease, and an independent prognostic factor in ovarian cancer (Stone et al., 2012), in line with our findings. Thrombocytosis is linked to thromboembolic complications in cancer and reported to be a driver for tumor growth and proliferation by stabilizing tumor vasculature preventing tumor hemorrhage (Stone et al., 2012). Collective data proved platelets could release some growth factors, platelet-derived growth factor (PDGF), platelet factor 4, transforming growth factor beta (TGF $\beta$ ), vascular endothelial growth factor (VEGF) and thrombospondin which function as potent mitogen or as adhesive glycoprotein for different cell types including ovarian surface epithelium (CaoLiu, 2007; Burger, 2011; Gavalas et al., 2013). These growth factors could stimulate ovarian cancer cells proliferation and adhesion to other cells leading to tumor growth and metastasis, respectively. Moreover, preclinical models have suggested that targeting the mechanisms involved may have therapeutic potential in ovarian cancer (Stone et al., 2012). Furthermore, EPO may be involved in the development of thrombocytosis associated with tumor anemia, and has been shown to promote platelet formation (Khorana, 2009). Notably, Interleukin-6 (IL-6) and granulocyte-macrophage colony stimulating factor (GmCSF) probably stimulated thrombopoiesis and may provoke thrombocytosis (van Rossum et al., 2009). In ovarian cancer, elevated IL- 6 produced by ovarian cancer cells in ascites had been associated with thrombocytosis (Gastl et al., 1993). Besides, low-molecular-weight heparin has been shown to improve survival in prospective clinical trials of other cancers, apparently beyond the effect of preventing vascular thromboembolic complications (Akl et al., 2007). Our findings of thrombocytosis as an independent unfavorable survival factor may suggest assessment of similar therapeutic approaches also in EOC 
Ying Chen et al

patients with thrombocytosis and also suggested that a subgroup of EOC cancer patients with high risk of venous thromboembolic events could benefit from long-term anti-coagulant prophylaxis to improve survival outcome.

Our study is not without limitations. The present study is in its retrospective analysis and the impact of possible coexisting inflammatory conditions potentially affecting the hematopoietic organ is not accounted for in our study. It remains questionable whether abnormal hematologic profile is simply an end result of tumor growth or the underlying killer causing mortality. Therefore, confirming the prognostic effect of pretreatment hematologic profile in studies with prospective design is mandatory.

In general, most of the patients undergoing surgery for ovarian cancer have their hematologic parameters examined routinely as a part of their preoperative work up. Importantly, our study illustrated that preoperative anemia, leukocytosis or thrombocytosis was associated with adverse characteristic features and poor prognosis in EOC. Furthermore, thrombocytosis may act as the independent indicator in evaluating the PFS and OS for EOC patients. Therefore, in our opinion, it is a cheap and easy method of obtaining prognostic information prior to surgery. The mechanisms linking preoperative hematological manifestations and EOC are poorly defined, as well as future studies linking these observations to clinical outcome and pathogenesis may be of interest in search for new strategies in EOC therapy.

\section{Acknowledgements}

This work was supported by Tianjin Health Bureau of Science and Technology Funds (2012KZ073) and National Natural Science Foundation (81302250).

\section{References}

Acs G, Xu X, Chu C, Acs P, Verma A (2004). Prognostic significance of erythropoietin expression in human endometrial carcinoma. Cancer, 100, 2376-86.

Akl EA, van Doormaal FF, Barba M, et al (2007). Parenteral anticoagulation for prolonging survival in patients with cancer who have no other indication for anticoagulation. Cochrane Database Syst Rev, 18, CD006652.

Antonioli L, Blandizzi C, Pacher P, Hasko G (2013) Immunity, inflammation and cancer: a leading role for adenosine. Nat Rev Cancer, 13, 842-57.

Ashour AA, Verschraegen CF, Kudelka AP, Kavanagh JJ (1997). Paraneoplastic syndromes of gynecologic neoplasms. J Clin Oncol, 15, 1272-82.

Burger RA (2011). Overview of anti-angiogenic agents in development for ovarian cancer. Gynecol Oncol, 121, 230-8.

Cao Y,Liu Q (2007). Therapeutic targets of multiple angiogenic factors for the treatment of cancer and metastasis. $A d v$ Cancer Res, 97, 203-24.

Cho MS, Bottsford-Miller J, Vasquez HG, et al (2012). Platelets increase the proliferation of ovarian cancer cells. Blood, 120, 4869-72.

Cordella C, Luebbers HT, Rivelli V, Gratz KW, Kruse AL (2011). An evaluation of the preoperative hemoglobin level as a prognostic factor for oral squamous cell carcinoma. Head Neck Oncol, 3, 35.

Cullis J. (2013). Anaemia of chronic disease. Clin Med, 13,
193-6.

Dicato M, Plawny L, Diederich M (2010). Anemia in cancer. Ann Oncol, 21, 167-72.

Gastl G, Plante M, Finstad CL, et al (1993). High IL-6 levels in ascitic fluid correlate with reactive thrombocytosis in patients with epithelial ovarian cancer. Br J Haematol, 83, 433-41.

Gavalas NG, Liontos M, Trachana SP, et al (2013). Angiogenesisrelated pathways in the pathogenesis of ovarian cancer. Int J Mol Sci, 14, 15885-909.

Gerestein CG, Eijkemans MJ, de Jong D, et al (2009). The prediction of progression-free and overall survival in women with an advanced stage of epithelial ovarian carcinoma. $B J O G, 116,372-80$.

Grivennikov SI, Greten FR, Karin M (2010). Immunity, inflammation, and cancer. Cell, 140, 883-99.

Gungor T, Kanat-Pektas M, Sucak A, Mollamahmutoglu L (2009). The role of thrombocytosis in prognostic evaluation of epithelial ovarian tumors. Arch Gynecol Obstet, 279, 53-6.

Hanahan D, Weinberg RA (2011). Hallmarks of cancer: the next generation. Cell, 144, 646-74.

Hardee ME, Arcasoy MO, Blackwell KL, Kirkpatrick JP, Dewhirst MW (2006). Erythropoietin biology in cancer. Clin Cancer Res, 12, 332-9.

Herzog TJ, Vermorken JB, Pujade-Lauraine E, et al (2011). Correlation between CA-125 serum level and response by RECIST in a phase III recurrent ovarian cancer study. Gynecol Oncol, 122, 350-5.

Holgersson G, Sandelin M, Hoye E, et al (2012). Swedish lung cancer radiation study group: the prognostic value of anaemia, thrombocytosis and leukocytosis at time of diagnosis in patients with non-small cell lung cancer. Med Oncol, 29, 3176-82.

Jung MR, Park YK, Jeong O, et al (2011). Elevated preoperative neutrophil to lymphocyte ratio predicts poor survival following resection in late stage gastric cancer. J Surg Oncol, 104, 504-10.

Khorana AA (2009). Cancer and thrombosis: implications of published guidelines for clinical practice. Ann Oncol, 20, 1619-30.

Li FX, Wei LJ, Zhang H, Li SX, Liu JT (2014). Significance of thrombocytosis in clinicopathologic characteristics and prognosis of gastric cancer. Asian Pac J Cancer Prev, 15, 6511-7.

Mabuchi S, Matsumoto Y, Isohashi F, et al (2011). Pretreatment leukocytosis is an indicator of poor prognosis in patients with cervical cancer. Gynecol Oncol, 122, 25-32.

Mroczko B, Groblewska M, Wereszczynska-Siemiatkowska U, et al (2007). Serum macrophage-colony stimulating factor levels in colorectal cancer patients correlate with lymph node metastasis and poor prognosis. Clin Chim Acta, 380, 208-12.

Njolstad TS, Engerud H, Werner HM, Salvesen HB, Trovik J (2013). Preoperative anemia, leukocytosis and thrombocytosis identify aggressive endometrial carcinomas. Gynecol Oncol, 131, 410-5.

Pelosof LC, Gerber DE (2010). Paraneoplastic syndromes: an approach to diagnosis and treatment. Mayo Clin Proc, $\mathbf{8 5}$, 838-54.

Qiu MZ, Xu RH, Ruan DY, et al (2010). Incidence of anemia, leukocytosis, and thrombocytosis in patients with solid tumors in China. Tumour Biol, 31, 633-41.

Qiu MZ, Yuan ZY, Luo HY, et al. (2010). Impact of pretreatment hematologic profile on survival of colorectal cancer patients. Tumour Biol, 31, 255-60.

Seo KH, Lee HS, Jung B, et al (2004). Estrogen enhances angiogenesis through a pathway involving platelet-activating 

factor-mediated nuclear factor-kappaB activation. Cancer Res, 64, 6482-8.

Siegel R, Naishadham D, Jemal A (2013) Cancer statistics, 2013. CA Cancer J Clin, 63, 11-30.

Stone RL, Nick AM, McNeish IA, et al (2012). Paraneoplastic thrombocytosis in ovarian cancer. $N$ Engl J Med, 366, 610-8.

Tomita M, Shimizu T, Hara M, Ayabe T, Onitsuka T (2008). Impact of preoperative hemoglobin level on survival of nonsmall cell lung cancer patients. Anticancer Res, 28, 1947-50.

Unal D, Eroglu C, Kurtul N, Oguz A, Tasdemir A (2013). Are neutrophil/lymphocyte and platelet/lymphocyte rates in patients with non-small cell lung cancer associated with treatment response and prognosis? Asian Pac J Cancer Prev, 14, 5237-42.

van Rossum AP, Vlasveld LT, Vlasveld IN, et al (2009) Granulocytosis and thrombocytosis in renal cell carcinoma: a pro-inflammatory cytokine response originating in the tumour. Neth J Med, 67, 191-4.

Weiss G, Goodnough LT (2005). Anemia of chronic disease. $N$ Engl J Med, 352, 1011-23.

Wheler J, Tsimberidou AM, Hong D, et al (2009). Survival of patients in a phase 1 clinic: the M.D. Anderson Cancer Center experience. Cancer, 115, 1091-9.

Yasuda Y, Fujita Y, Masuda S, et al (2002). Erythropoietin is involved in growth and angiogenesis in malignant tumours of female reproductive organs. Carcinogenesis, 23, 1797-805. 